\title{
A Conceptual Approach to Patient-Physician Relationship
}

\section{Hasta-Hekim İlişkisine Kavramsal Yaklaşım}

\author{
Genco Görgü̈, Makbule Neslişah Tan², Vildan Mevsim²
}

\begin{abstract}
The quality of the patient-physician relationship affects the patient's compliance with the treatment and satisfaction with the interview. Szasz and Hollender (1956) described three types of patient-physician relationships. In the relationship based on activity-passivity, the physician is equipped with broad powers, regardless of the patient's consent. Relationship based on guidance-cooperation defines the relationship between the patient who is ready to apply the commands of the physician and the physician who offers his professional experience. Relationship based on mutual participation is the patient-physician relationship when the physician provides professional support for the individual to contribute to his or her health. Patientphysician relationship was modeled by Emanuel EJ and Emanuel LL (1992) with a four-component classification. The physician who adopts authoritarian attitude in the paternalistic model can ignore his patient's preferences. In the informative model, all the information about the situation is presented to the patient, the patient makes his own choice and the physician applies the selected medical intervention. In the interpretive model, the physician sets out the patient's expectation, while doing so, takes the patient's values as reference and shapes the treatment on this basis. In the deliberative model that encourages shared decision-making between the physician and the patient, the physician and the patient discuss mutually about what options the patient can choose during the treatment process and the path to be followed. It should not be forgotten that the type of relationship to be adopted in the clinical interview may vary depending on the condition of the patient and the nature of the disease.
\end{abstract}

Key words: Patient-physician relationship, guidance-cooperation, paternalistic model

\section{ÖZET}

Hasta-hekim ilişkisinin niteliği, hastanın tedaviye gösterdiği uyumu ve görüşmeden memnuniyetini etkilemektedir. Szasz ve Hollender (1956) üç tür hasta-hekim ilişkisi tanımlamışlardır. Etkinlik-edilgenlik temeline dayanan ilişkide hekim hastanın onamından bağımsız olarak, geniş yetkilerle donanmıştır. Yol gösterme-iş birliği etme temeline dayanan ilişki hekimin komutlarını harfiyen uygulamaya hazır hasta ile hastanın karşısında mesleki deneyimini sunan hekim arasındaki ilişkiyi tanımlar. Karşılıklı katılım temeline dayanan ilişki hekimin, bireyin kendi sağlığına katkı sunması için profesyonel destek sağladığı hasta-hekim ilişkisidir. Hasta-hekim ilişkisi Emanuel EJ ve Emanuel LL (1992) tarafından dört bileşenli bir sınıflama ile modellenmiştir. Paternalistik modelde otoriter tutumu benimseyen hekim hastasının tercihlerini görmezden gelebilir. Bilgilendirici modelde durumla ilgili tüm bilgiler hastaya sunulur, hasta kendi seçimini yapar ve doktor seçilen tıbbi müdahaleyi uygular. Yorumlayıcı modelde hekim, hastanın beklentisini ortaya çıkarır, bunu yaparken hastanın değerlerini referans alır ve tedaviyi bu temelde şekillendirir. Hekim ve hasta arasında ortak karar vermeyi teşvik eden uzlaşmacı modelde hekim ve hasta, hastanın tedavi sürecinde ne tür seçenekleri tercih edebileceği ve nihai olarak izlenecek yol konusunda karşllıklı tartışılar. Unutulmamalıdır ki, klinik görüşmede hangi ilişki türünün benimseneceği hastanın durumuna ve hastalığın özelliğine göre değiş̧ebilecektir.

Anahtar kelimeler: Hasta-hekim ilişkisi, yol gösterme-iş birliği etme, paternalistik model

Received / Geliş tarihi: 07.04.2020, Accepted / Kabul tarihi: 06.01.2021

${ }^{1}$ T.C. Sağlık Bakanlığı Marmara İlçe Devlet Hastanesi, Balıkesir, TÜRKIYYE

${ }^{2}$ Dokuz Eylül Üniversitesi Tıp Fakültesi, Aile Hekimliği Anabilim Dalı, İzmir, TÜRKIYYE

*Address for Correspondence / Yazışma Adresi: Makbule Neslişah Tan, Dokuz Eylül Üniversitesi Tıp Fakültesi, Aile Hekimliği Anabilim Dalı, İzmir TURKEY.E-mail: drnesli293@hotmail.com

Görgü G, Tan MN, Mevsim V. A Conceptual Approach to Patient-Physician Relationship. TJFMPC, 2021;15(1): 14-18.

DOI: $10.21763 /$ tjfmpc.716051

Görgü ve ark., TJFMPC www.tjfmpc.gen.tr 2021; 15 (1) 


\section{Gİiş̧}

Hekimlik mesleği; insanlara sağlık alanında yardımcı olabilmek için, onlarla etkili bir iletişim kurmayı gerektirir. Hasta-hekim ilişkisi, hastanın tedaviye gösterdiği uyumu ve görüşmeden memnuniyetini doğrudan etkilemektedir. Hekimin yalnızca bir teknisyen bakış açısıyla yaklaşım göstermesi tedaviye ilişkin sonuçları olumsuz etkileyecektir. Etkin iletişimin kurulamamas1, hekimlerin tanı ve tedaviye giden yolda araç olarak hastaların ifadelerinden daha çok laboratuvar sonuçlarını kullanmasına neden olmaktadır. ${ }^{1}$

1840 y1lında Fransız psikiyatrist Leuret'in aktörü olduğu bir tarihsel anektod hasta-hekim ilişkisinin geçmişten süregelen kalıplarına dikkat çekmektedir. Doktor Leuret hastası Bay A.'dan deliryumla ilişkili sanrılarını detaylı olarak tasvir etmesini ister. "Bunların hepsi sadece delilikten kaynaklanıyor, anlaştık mı? Artık bunlara inanmayacağınıza dair söz verin" der. Hasta bir süre düşündükten sonra gönülsüzce hekimini onaylar. "Bu yeterli olmaz, öncesinde benzer sözler vermenize rağmen tutmadınız" diye çıkışır doktor, hemen ardından musluğu açar, hastanın başından aşağı soğuk suyu boşaltır. "Evet, evet bence de deliyim ben" der hasta. Bunun üzerine Doktor Leuret soğuk suyu kapatır ve hastasını sorgulamaya kaldığ1 yerden devam eder. Süregelen belirtilerinin delilikten ileri geldiğini beyan eden hasta tıbbi görüşmeyi şu sözlerle tamamlar: "Kabul ediyorum çünkü beni buna zorluyorsunuz.”

Tıbbın kökenleri ve kliniğin evrimi ile ilgili çalışmaları bulunan Fransız düşünür Michel Foucault'a göre bu doktorun hedefi hastanın durumunu anlamakla vakit kaybetmeksizin, doğru ve gerçek olanı hastaya dikte etmektir. ${ }^{2}$ Ele aldığımız örnekte; kendisine dair alg1 ve duygularını aktaramayan hastanın, doktor nezdinde saptanmış durumunu, adeta baskı altında gelen bir itiraf gibi kabullenmesine şahit oluruz. Hastanın düşünceleri gerçekle bağdaştırılmaya çalışılırken hekim merkezli bir kurgu içinde kaybolan hasta, hastahekim ilişkisine yabancılaşabilir. Ancak tıp literatürüne baktığımızda işlerin artık 19. yüzyıldaki gibi yürümediğini ve bu tür bir ilişkinin tek seçenek olmadığını görüyoruz.

\section{Hasta-Hekim İlişkisini Sınıflandırmak}

Szasz ve Hollender (1956), etkinlik-edilgenlik temeline dayanan ilişki, yol gösterme-iş birliği etme temeline dayanan ilişki ve karşılıklı katılım temeline dayanan ilişki olmak üzere üç tür hasta-hekim ilişkisi tanımlamışlardır. ${ }^{3}$

Etkinlik-edilgenlik temeline dayanan ilişki; hekimin; sonsuz bir durağanlık içerisinde teslim olan hastaya "bir şeyler" yaptığı ilişki olarak tanımlanır. ${ }^{4,5} \mathrm{Bu}$ ilişki biçimi çerçevesinde hastanın payına düşen, hiç repliği olmayan bir figüran rolüdür. ${ }^{5}$ Ataerkil tutum ve davranışlar etrafında şekillenen ilişki biçimi olarak betimlenir. Hekimin prosedürleri uygulayan teknisyen olduğu varsayılır. ${ }^{6}$ Hastanın onamından bağımsız olarak; hekim, hastanın iyiliği için geniş yetkilerle donanmıştır. Hasta, tam edilgenlik halindedir ve bilinci olsun olmasın iradesini yansitabilecek rolü yoktur. ${ }^{7} \mathrm{Bu}$ ilişki, acillerde karşımıza çıkan hasta-hekim ilişkisine bir örnektir. ${ }^{3}$

Yol gösterme-iş birliği etme temeline dayanan ilişki; iş birliğine ve hekimin komutlarını harfiyen uygulamaya hazır hasta ile mesleki deneyimini sunan hekim arasındaki ilişki olarak betimlenebilir. Burada hasta k1smen aktif konumdadır. Fakat tanı ve tedavi çıktılarına dair sorumluluk tamamen hekime aittir. Akut, özellikle enfeksiyöz hastalık süreçlerinde daha sık görülen bu ilişkide; hasta tedavinin ne şekilde yapılacağını bilir ve tıbbi kararları gerçeğe uygun olarak değerlendirir. ${ }^{8}$ Hekim, tıbbi görüşme sürecinin kılavuz kaptanıdır. ${ }^{9}$ Sonuç olarak hasta, mesleki bilgisinin 1şı̆̆ında gerekli tedaviyi tebliğ eden hekime uyum gösterir. ${ }^{7,9}$

Karşılıklı katılım temeline dayanan ilişki; hekimin, bireyin kendi sağlığına katkı sunması için profesyonel destek sağladığ ilişkidir. $^{4} \mathrm{Bu}$ ilişkide, tanısal yaklaşımdan tedavi önerilerine kadar olan tüm klinik görüşme sürecinde, hasta ve hekimin ortak kararı mevcuttur. Bu ortaklık sorumluluğun da paylaşılmasını içermektedir. ${ }^{10}$ Hekimle birlikte; kendi hastalık deneyimine sahip olan hasta, aynı hedef için ortak mesai harcar. ${ }^{11} \mathrm{Bu}$ ilişki, kronik hastalıkların yönetiminde olduğu gibi, hastanın seçenekleri değerlendirdiği ve hekim tarafından karar mekanizmasına katılımının desteklendiği bir ilişkidir. $^{7-9}$

\section{Hasta-Hekim İlişkisi Modelleri}

Hasta-hekim ilişkisi kavramı; Emanuel EJ ve Emanuel LL (1992) tarafindan, hekimler, hastalar ve yardımcı sağlık personeli arasındaki bağların anlaşılabilirliğini geliştirmek, bu paydaşlar etrafındaki klinik işleyişin akışını kolaylaştırmak ve verimli hale getirmek üzere; paternalistik model, bilgilendirici model, yorumlayıı model ve uzlaşmacı modeli içeren dört bileşenli bir sınıflama ile modellendirildi. ${ }^{12}$

Paternalistik model: $\mathrm{Bu}$ modelde, sağlık için yapılacak en doğru girişimin belirlenmesini sağlayan objektif ölçütler olduğu kabul edilir. Objektif olarak her şeyi düşündüğüne inanan ve hasta için en iyi olacak tedaviyi kendisinin belirleyeceğini düşünen hekim; kendi uygun 
gördüğü müdahalenin hasta tarafından onaylanmasını sağlayacak, seçilmiş verileri sunar. Kimi zaman hastanın çıkarları için, hastanın özerkliği sınırlandırılabilir. Hekim hastanın kendisine ileride müteşekkir olacağına inanmaktadir. $^{12}$

Hekim, neyin hasta için en doğru olduğunu ifade edip uygulayarak, hastanın savunucusu gibi davranır. ${ }^{4,12,13}$ "Hasta için en iyi olana" ulaşmak amacıyla, tıbbi gereksinimler bilgisinin sınırlarını aştığında konsültasyon ve sevk mekanizmalarını işletir. Hastanın söz hakkı, hekimin teklif ettiği "mümkün olan en iyiyi" kabul edip etmemesi ile sinırlıdır. ${ }^{12}$

Paternalizmde hekimin, hastanın iyiliğini ondan daha iyi düșünebileceği varsayılır. Hasta yeterli donanımda olsa bile kendisi için en doğru olanın ne olduğuna karar veremeyeceği savıyla hareket edilmektedir. Paternalizm, rizası yeterince sorgulanmaksızın, hasta özerkliğinin ihlal edilmesi sonucunu doğurur. Bir başka ifadeyle, hasta menfaatleri için hastanın iradesi zedelenmektedir. ${ }^{14}$ $\mathrm{Bu}$ bağlamda, hekim, bilgi ve teknik donanımıyla üstün, etik duruşuyla meşrudur, gerekli hallerde hastanın öncelik ve tercihlerini göz ardı eder veya aşar. $^{15}$

Paternalist yaklaşımın aile hekimliği disiplini bağlamında ele alındığındaki temel kısıtlılıklarından birisi hasta-hekim ilişkisini hekim, hasta ve hastalıktan ibaret olmak üzere yalnızca üç boyuta indirgemesidir. Ekonomik, ailevi ve toplumsal ilişkilerin bileşkesinde yaşamını sürdüren hasta, kendi koşulları ve tercihlerini karar mekanizmasına katamadıkça, hasta-hekim ilișkisindeki özerk alanı daralır ve tıbbi sürecin etkinliği ve sürdürülebilirliği olumsuz yönde etkilenir. $^{16}$

Tıbbi pratikte paternalizmi tümden dışlamak olası görülmese de bu yaklaşımın çerçevesini iyi çizmek, bu çerçeveyi olabildiğince dar tutmak ve bu davranışın haklı gerekçelerini çok iyi ortaya koymak gereklidir. Bunlar; (1) tedavinin hastada yaratacağı olumlu etkinin çok önemli ve mutlak olması, (2) tedavinin olas1 yan etkilerinin, tedavinin faydaları ile mukayese edildiğinde çok daha az olması, ve (3) hastanın tedaviyi reddinin gerçekle bağdaşmadığına dair somut kanıtlar bulunmasıdır. Hekim nesnel tavrını korurken en azından hasta ile empati yapabilmelidir. ${ }^{15}$

$\mathrm{Bu}$ modelde hekim mutlak egemendir. Hekimin hastasına fayda sağlama amacı, buna gücü yetmesi ve hastanın beklentisi; hekimi ilişkide dizginleri elinde tutan mutlak güç olarak atar. Bu açıdan baktığımızda, hekimlik mesleği ve klinik ortam mutlak surette içerisinde belli bir "otorite" ihtiva etmektedir. Otoriter tutumu benimseyen hekim, hastasına tıbbi katkı sunma kaygısıyla hastasının tercih ve bilinçli eylemlerini görmezden gelebilir ve hastanın tıbbi durumunu hastadan saklamakta ya da yeterince detaylı bilgi vermemekte bir sakınca görmeyebilir. ${ }^{9}$

Paternalistik yaklaşımın yalnızca hastanın onam verme şansının olmadığı, mental ve bilişsel olarak onam verme şansı olsa tedaviyi kabul edeceği öngörülen koşullarda benimsenmesi önerilir. ${ }^{12}$ Ancak paternalistik yaklaşıma dönük eleştirileri ele alırken içinde yaşanılan toplumun sosyokültürel ve sosyoekonomik düzeyi de ihmal edilmemelidir.

Bilgilendirici model: Bilimsel model ya da tüketim modeli olarak da isimlendirilen bu hastahekim ilişkisi modelinde amaç, hastaya durumla ilgili bütün bilgilerin sunulması, hastanın kendi iradesiyle tercihte bulunması ve hekimin seçilen tedaviyi uygulamasıdır. Bu süreci sağlıklı yürütmek için hekim, hastayla; hastalığının niteliğini ve genel durumunu, muhtemel tanı ve tedavi olasıllklarını, bu seçeneklere dair kâr-zarar hesaplarını ve konuyla ilgili doğabilecek belirsizlikleri paylaşır. ${ }^{12}$

Hastaya sağlık durumuna dair tüm bilgiler ve seçenekleri sunulmuştur. Hasta hangi müdahalenin yapılacağına kendi değerleri ile karar verir. ${ }^{12}$ Hekimin kendisinin ve hastasının değerlerine ilişkin perspektifi bu modelde yer almaz. ${ }^{9}$ Hekimin alanı, uzmanlık alanında deneyim sahibi olmak, nitelikli bilgi sağlamak ve lüzumu halinde diğer hekimlere danışmakla sınırlıdır. Tıbbi kararlar hasta iradesiyle verilmektedir. ${ }^{12}$ Ancak atılacak adımın hastanın kararına bırakılması, hastanın hisleri ve beklentisinin ne olduğu konusunda belirsizlik yaşadı̆̆ 1 durumlarda etkin bir hasta-hekim ilişkisini sağlayamayacaktır. Hekimin çizdiği çerçeve içerisindeki aynaya bakan hasta, kendisini tıbbi sorunlar ve korkutucu gerçeklerle baş başa kalmış hissedebilir. ${ }^{17}$ Paternalistik modelde hekimin mutlak belirleyici konumu, bu modelde hasta lehine dönmektedir.

Yorumlayıc model: $\mathrm{Bu}$ modelde hastahekim ilişkisinin amacı, hastanın beklentisini gün 1şığına çıkarmak, bunu yaparken hastanın değerlerini referans almak ve tedaviyi bu temelde şekillendirmektir. ${ }^{12}$ Bilgilendirici modele benzer olarak bu modelde de hasta içinde bulunduğu sağlık durumu ve müdahalelerin olası riskleri konusunda aydınlatılır. Yorumlayıcı modelde hekim, hastanın tıbbi görüşmede örtündüğü tutumun altındaki değerleri yansıtmasına aracı olup, bu değerleri hasta adına yorumlamaktadir. ${ }^{9}$

$\mathrm{Bu}$ modele göre, hastanın değerleri farklı zamanlarda farklı seyir gösterebilir. Çoğu zaman bu değerler tam olarak olgunlaşmamıştır ve hasta 
bunları sadece kısmen sezebilir, tam olarak anlamayabilir. Değerler, yaşam pratiğinde karş1 karşıya kalınan koşullarla çatışabilirler. Bu nedenle, hastayla ilgilenen hekim bunları çözümlemeli ve anlaşılır bir duruma getirmelidir. Hekim, en uygun yaklaşımı hastasına önerir ve dikte eden bir tavırdan sakınır. Son söz hastaya aittir. Hekim karar veren bir yargıç konumunda değil, hastanın farkındalık ve sorumluluk bilinci geliştirmesi için yardımcı olan ve karar verme mekanizmasına katılımı kolaylaştıran bir katalizördür. ${ }^{12}$

Yorumlayıc1 model güncel genel pratisyenlik yaklaşımı için uyumlu bir perspektif sunar. Hekim, biyolojik verileri, bireyin sağlığına ilişkin algısını ve kanıt değeri yüksek bilgiyi entegre eder. $^{18} \quad$ Böylelikle kişiselleştirilmiş tedavi yaklaşımları ortaya konabilir. Sağlık hizmetlerinin yönetimi ve kalite standartlarının değerlendirilmesi adına da uygun bir zemin oluşur. ${ }^{19,20}$

$\mathrm{Bu}$ modelde, hekim olası tüm bilgiyi paylaşır, hastanın değerlerini ortaya çıkarmasına yardımcı olur ve hangi tıbbi girişimlerin bu değerleri gerçekleştirmeye yardım edeceğini söyler. Hekim bu noktada bilgilendirmekle kalmaz, aynı zamanda hastay1 ortak bir zemine davet eder. Hekimlerin kendi değerlerini dayatma eğilimi, hastaların da bunu kabul etmeye meyilli bir konumda olmas1, hasta-hekim ilişkisinde yorumlayıcı modelin maksadını aşarak yine ataerkil bir yaklaşıma savrulmasına neden olabilir. ${ }^{12}$

Uzlaşmacı model: Bu hasta-hekim ilişkisi modeli hastanın, sağlığa dair önceliklerini su yüzüne çıkarmasına ve sağlık durumuna en uygun olan adımı tercih etmesine katkı sunmaktadır. Bu sonuca ulaşmak için hekim, hastanın tıbbi durumu hakkındaki verileri hastayla paylaşacak ve eldeki seçeneklerin ifade ettiği klinik anlamı açığa çıkarmaya yardımcı olacaktır. Sağlığa dair bazı değerlerin neden daha ön planda olduğu ve öncelikli olarak ele alınması gerektiği hususunda tavsiyelerde bulunmak hekimin görevleri dâhilindedir. Hekim ve hasta, hastanın tedavi sürecinde ne tür seçenekleri tercih edebileceği ve son olarak izlenecek yol konusunda karşılıklı görüşürler ve tıbbi durum konusunda ortak anlayış geliştirirler. Tercih hakkının saklı olduğunu bilen hasta, hekim tarafından aydınlatılmasının ardından, nesnel bir perspektifle sunulan seçenekleri değerlendirir ve atılacak adımı belirleme noktasında desteklenir. Hekimin hastayı tıbbi doğruya ikna etme sorumluluğu saklıdır ancak bir dayatmadan ziyade hastanın özerkliğine saygı duyulan bir uzlaşı süreci işletilir. $^{12}$

Uzlaşmac1 model, klinik görüşmede doğan etik ve teknik sorunların karmaşık doğasına karşı; hasta merkezlilik doğrultusunda çözüm üretebilmek için önemli bir araçtır. Hekimi hastanın önceliklerini ön planda tutması konusunda cesaretlendirir. ${ }^{21,22}$

Uzlaşmacı model hasta-hekim ilişkisinde en ideal yaklaşım olarak kabul görmektedir. ${ }^{12,23}$ Tedavi için doğru seçeneğin çok net olmadığı, problemi çözebilmek adına hastanın yaşam tarzı ve tutum değişikliğine gitmesinin gerekli olduğu, bireyin yetmezlik ve engel durumu ile birlikte yaşamasının gerektiği hallerde altın standart bir model olarak göze çarpmaktadır. ${ }^{9}$ Hekim ve hasta arasında ortak karar vermeyi teşvik ettiği için, özellikle kronik hastalık yönetiminde ideal bir model olarak gösterilmiştir. ${ }^{24}$

\section{SONUÇ}

Güncel yaklaşımlar 1şı ğında, bilinci açık ve bilișsel yeterliliği olan bir hastanın başvuru sahibi olduğu durumlarda karşılıklı katılım temeline dayanan uzlaşmacı modelin tercih edilmesinin gerektiği; bunun dışındaki bir ilişki türünü benimsemenin uygun olmadığ 1 görülmektedir. ${ }^{15}$

Unutulmamalıdır ki, klinik görüşmede hangi ilişki türünün benimseneceği hastanın durumuna (kişiliği, eğitim düzeyi, entelellektüel yeterliliği vb.) ve hastalığın özelliğine (akut veya kronik olması vb.) göre değişebilecektir. ${ }^{9}$ Tıp mesleğinin doğal bir fenomeni olan belirsizlik; hekimin kendi mesleki bilgisi ve hastanın tercihlerinin yanı sıra, "sense clinique" yani mesleki sezgiselliğe de alan bırakmasını gerektirebilir. Algoritma ve kılavuzlar ne kadar yaygınlaşırsa yaygınlaşsın; klinik ortamın dinamik yapısı hekimin sezgileriyle inisiyatif alması gereken durumları yaratacaktır. Böyle anlarda herhangi bir modele dogmatik bir tutumla bağlı kalmak hastanın çıkarlarına zarar verebilir. Modeller arası geçişkenlik ve kombinasyonlar birer problem çözme aracı olarak kullanılabilir

Hasta hakları alanında yaşanan yeni gelişmeler, mediko-legal yükümlülükler ve birinci basamakta hasta-hekim görüşmesini değerlendiren güncel çalışmaların sonuçları göz önünde bulundurulduğunda, klinik uygulamalarda hekimin sorumluluk alanının sınırlarının yeniden çizilmekte olduğu görülür. Hasta katılımının sağlandığı bir hasta-hekim ilişkisi bu yeni duruma ilişkin problemleri çözme kabiliyetinin arttırılması açısından gereklidir. $\mathrm{Bu}$ amaca ulaşmak adına yalnızca hekimin sorumluluk almasını beklemek birinci basamak ortamına özgü bütüncül yaklaşımı tesis etmek ve bireyin tam iyilik halini sürdürmek adına yeterli değildir. Toplumun sosyokültürel yapısının oldukça zengin olduğu, hasta profilinin dramatik ölçüde değişkenlik gösterdiği ve sınırlı hekim sayısıyla geniş kitlelere hizmet sunulan koşullarda, karşılıklı katılım temeline dayalı 
ilişkinin uygulanması elzem olmakla birlikte oldukça da zordur. Bu ilişkiyi kurmak için ihtiyaç duyulan, hastanın varoluşunun tüm boyutlarını ele alan yaklaşıma; birinci basamak ortamındaki doğrusal, uzun soluklu ve katılımcı bir hasta-hekim ilişkisi aracılığgyla ulaşılabilir.

\section{KAYNAKLAR}

1) Ataç A. İletişim, tıp etiği ve tıp uygulamalarında yansıması. Hacettepe Tip Dergisi 2009;40:8995.

2) Foucault M. Hermenötiğin Kökeni: Kendilik Hakkında-Dartmouth Konferansları 1980. Çiltaş Solmaz Ş, çev.editörü. L'origine de L'herméneutique de soi. İstanbul: Ayrıntı Yayınlari; 2017.p.19-20.

3) Szasz TS, Hollender MH. A contribution to the philosophy of medicine; the basic models of the doctor-patient relationship. AMA Arch Intern Med 1956;97(5):585-592.

4) Habiba MA. Examining consent within the patient-doctor relationship. J Med Ethics 2000;26(3):183-187.

5) Öngören B. Hekim-hasta ilişkisi ve sağlık hizmetlerinde iletişim 2. Tibbi Sosyal Hizmet Dergisi 2017;(10),57-69.

6) Epstein RM. The patient-physician relationship. In: Mengel MB, Holleman WL, Fields SA, editors. Fundamentals of Clinical Practice. Boston:Springer; 2002. p.403-429.

7) Oğuz NY. Klinik uygulamada hekim-hasta ilişkisi. Tibbi Etik 1995;3(2-3):59-65.

8) Vertinsky IB, Thompson WA, Uyeno D. Measuring consumer desire for participation in clinical decision making. Health Serv Res 1974;9(2):121-134.

9) Atıcı E. Hasta-hekim ilişkisi kavramı. Uludağ Üniversitesi Tıp Fakültesi Dergisi 2007;33(1):45-50.

10) Coulter A. Paternalism or partnership? Patients have grown up-and there's no going back. BMJ 1999;319(7212):719-720.

11) Tuckett D, Boulton M, Olson C, Williams A. Review of Meetings between experts: an approach to sharing ideas in medical consultations. Family Systems Medicine 1987;5(2),264-266.
12) Emanuel EJ, Emanuel LL. Four models of the physician-patient relationship. JAMA 1992;267(16):2221-6.

13) Lazaro J. Doctors' status: changes in the past millenium. Lancet 2000;354:17.

14) Savulescu J. Rational non-interventional paternalism: why doctors ought to make judgements of what is best for their patients. J Med Ethics 1995;21(6):327-33.

15) Örs Y. Geçmişte ve günümüzde hekim-hasta ilişkisi. Tıp Dünyası 1975;48(6):224-30.

16) Siegler M. The progression of medicine. Arch Internal Medicine 1985;145:713-715.

17) Wells RE, Kaptchuk TJ. To tell the truth, the whole truth, may do patients harm: the problem of the nocebo effect for informed consent. Am J Bioeth 202;12:22-29.

18) Salmon P. Conflict, collusion or collaboration in consultations about medically unexplained symptoms: the need for a curriculum of medical explanation. Patient Education and Counseling 2007;67:246-54.

19) Balint $M$. The doctor, his patient, and the illness. Lancet 1955;1:683-8.

20) Pendleton D, Schofield T, Tate P, Havelock P. The consultation: an approach to learning and teaching. London: Oxford University Press; 1984. p:34-38.

21) Epstein RM, Street RL Jr. The values and value of patient-centered care. Ann Fam Med 2011;9(2):100-103.

22) Entwistle VA, Cribb A, Watt IS, Skea ZC, Owens J, Morgan HM, et al. "The more you know, the more you realise it is really challenging to do": tensions and uncertainties in person-centred support for people with longterm conditions. Patient Educ Couns 2018;101(8):1460-1467.

23) Carvallo A. Physicians and professionalism. patients and information. Rev Med Chil 2005;133(2):253-258.

24) Borza LR, Gavrilovici C, Stockman R. Ethical models of physician-patient relationship revisited with regard to patient autonomy, values and patient education. Rev Med Chir Soc Med Nat Iasi 2015;119(2):496-501. 